\title{
THE ROLE OF MAGNETIC RESONANCE MUSCULOSKELETAL IMAGING IN EVALUATION OF SPORTS INJURIES OF THE KNEE JOINT
}

\author{
Amr O. Khalil*, Donald Resnick**, Ayman F. Zeid*\& Fatma M. Zaiton* \\ Radiology Department of Zagazig University *, Radiology Department of University of California San \\ Diego**
}

\begin{abstract}
Aim: to evaluate the role of magnetic resonance imaging in the assessment of sport injuries of the knee joint as an integral part of the musculoskeletal system.

Methods: This study was done as a combined study between the Radiology Department of Zagazig University and the Radiology Department of University of California San Diego. It was conducted on 50 patients who were referred to the Radiology Department of the University of California San Diego. The patients were examined after sustaining different sports injuries of the knee joint. All the 50 patients were subjected to full history taking and Magnetic Resonance Imaging on the knee joint. The Magnetic Resonance Imaging results of 33 of these patients were compared with the results of knee arthroscopy.

Results: The study included 50 patients complaining of sports related knee pain. The age of the patients ranged from 15 to 55 years with a mean age of 29.68 years. Most of the patients were males (38 patients), while 12 patients were females. The leading sports for knee injuries in this study were soccer, American football and running. The most common knee lesions were anterior cruciate ligament lesions (19 patients) and meniscal lesions (18 patients). In comparison with knee arthroscopy, magnetic resonance imaging revealed an overall $93.9 \%$ sensitivity and $66.6 \%$ specificity.

Conclusion: Although arthroscopy has been considered the gold standard in knee sports injuries evaluation, MRI remains a reliable non-invasive modality that can reduce the use of diagnostic arthroscopy for evaluation of ligamentous, meniscal, bony and cartilaginous lesions.

Keywords: magnetic resonance imaging, knee, sports injuries, musculoskeletal, anterior cruciate ligament, meniscus, ligaments, tendons.
\end{abstract}

\section{INTRODUCTION}

$\mathbf{P}$ romotion of a physically active lifestyle is encouraged worldwide, particularly with regard to the many health benefits. It helps prevent obesity and has long-lasting benefits on bone health (1). Unfortunately, increased intensity and volume of sport practice lead to a higher rate of acute and overuse injuries (2).

Sports-related knee injuries are common, with contact sports and sports involving twisting movements being the most frequent causes. Sports injuries may affect any of the knee structures, including ligaments, menisci, bones, cartilage and peri-articular soft tissues. However, relatively few injuries involve isolated structures, with complex injuries affecting multiple structures being much more common (3).

Over the past 20 years, magnetic resonance imaging (MRI) has become the premier, first-line imaging study that should be performed in the evaluation of the painful knee (4). It is now widely used for imaging injuries of internal structures of the knee, and has replaced conventional arthrography and diagnostic arthroscopy. It is superior to computed tomography (CT) for imaging of soft tissue structures (3).
MRI is performed more commonly on the knee than on any other joint, and it is an excellent diagnostic tool that can aid in the evaluation of a host of sports-related injuries involving the ligaments, tendons, menisci, osseous structures, and articular surfaces. It has currently become the most widely used non invasive imaging method for detecting meniscal injuries, with a reported diagnostic accuracy of as high as $98 \%$, compared to arthroscopy, remaining the gold standard for confirming the diagnosis of meniscal tear (5).

Magnetic resonance imaging also provides high anatomic and pathologic definition of soft tissue, ligaments, fibro-cartilage, and articular cartilage. Fast spin-echo (FSE) imaging, used in conjunction with fat-suppression (FS) MR techniques, has extended the sensitivity and specificity of MR in the detection of articular cartilage injuries and the evaluation of meniscal tears. Additional advantages of MR imaging are multi-planar and thin section capabilities and the ability to evaluate subchondral bone and marrow (6).

Knee injuries are common at all levels of sporting activities and MR imaging plays an important role in evaluating the individual internal structure of the knee (3). 


\section{METHODS}

This study was done as a combined study between the Radiology Department of Zagazig University and the Radiology Department of University of California San Diego (UCSD). It was conducted on fifty patients who were referred to the Radiology Department of UCSD. The patients were examined after sustaining different sports injuries of the knee joint.

The patients population consisted of 38 males and 12 females with age ranging from 15 to 55 years with mean age of 29.68 years. 11 patients had injuries caused by soccer, 7 patients had injuries caused by American football and 7 patients had injuries caused by running. Other sports that caused knee injuries were tennis, skating, surfing, bicycling, martial arts, hiking, softball, aerobics, golf, gymnastics, volleyball and wrestling.

All the fifty patients were subjected to full history taking and Magnetic Resonance Imaging (MRI) on the knee joint. The MRI results of thirty three of these patients were compared with the results of knee arthroscopy. An informed written consent was taken from each patient.

\section{Magnetic Resonance Imaging:}

MRI examinations were acquired in the Radiology Department of UCSD by a 3 Tesla GE and by a 1.5 Tesla GE MRI machines. Patients were referred to the MRI unit, the Musculoskeletal section after sustaining sports injuries to their knee joints. The patients laid in supine position feet first using the Knee coil (wraparound). The knee was placed into the coil with $10-15^{\circ}$ external rotation. The joint was centered and secured in the coil. The other leg was cushioned. Scan planes included sagittal, coronal and axial planes. The main sequences used were Proton Density with fat suppression, T1 WIs, T2 WIs, T2* (gradient echo) and STIR. T2-weighted pulse sequence was acquired by fast spin echo technique (FSE). Fat suppression was done on PD, T2 and T1 weighted pulse sequences by frequency selective presaturation (or chemical shift). An alternative method to suppress fat was STIR (Short Tau Inversion Recovery).

\section{Knee arthroscopy:}

Knee arthroscopy was done at the Orthopedic Surgery section of UCSD by orthopedic surgeons. It was carried out to thirty three out of the fifty patients that had sports injuries and did MRI examination. It was done during a period ranging from two weeks to three months after doing the MRI.

\section{Statistical analysis:}

Data obtained from both Knee MRI and arthroscopy was collected and compared. Statistical analysis was performed using SPSS software. The degree of correlation between different parameters were evaluated by using the chi-square test. A difference of $\mathrm{p}<0.05$ between groups was considered significant. The accuracy, sensitivity, specificity, PPV and NPV of the knee MRI were compared to those of the knee arthroscopy.

\section{RESULTS}

The study included fifty patients complaining of sports related knee pain, only 3 patients $(6 \%)$ were with normal MRI findings and 47 patients $(94 \%)$ were with abnormal MRI findings.

The age of the patients ranged between 15 and 55 years with a mean age of 29.68 years. The most frequently involved age group was from 20-24 years (Table 1). Regarding sex distribution, 38 patients $(76 \%)$ were males, while 12 patients $(24 \%)$ were females

The site of knee joint injury varied from a patient to another affecting the ACL (fig. 1), the PCL, the menisci (fig. 2), the collateral ligaments (fig. 3), the bone (fig. 4), the cartilage (fig. 5) and the popliteal cyst causing its rupture (fig. 6). Table 2 shows the distribution of patients according to the site of knee injuries.

From those 47 patients with abnormal MRI findings, 16 patients $(34 \%)$ were represented with isolated injury and 31 patients $(66 \%)$ were represented with combined injuries.

The leading sports for knee injuries were soccer, American football and running. Knee sports injuries were also caused by other sports as detailed in table 3.

From those 33 patients compared with arthroscopy, 15 patients had ACL injuries and 10 patients had meniscal injuries. From those compared 15 patients with ACL injuries, 13 patient $(86.6 \%)$ were true-positive. Also, from those compared 10 patients with meniscal injuries, 8 patients $(80 \%)$ were true-positive (table 4).

The 19 patients that had ACL injuries all showed either focal or diffuse high ACL signal on fat suppressed PD-WIs representing 100\%. Other signs of ACL injuries included partial or complete interruption of fibers (fig. 1) that was seen in 9 out of the 19 patients representing $47.4 \%$ and 
ligamentous laxity that was seen in 8 out of the 19 patients representing $42.1 \%$.

Thirty three patients were compared with arthroscopy as the gold standard for diagnosing knee lesions. From those thirty three patients, three patients had no abnormal MRI findings. In correlation with knee arthroscopy, morphological analysis was true-positive in $28(93.3 \%)$ patients of the compared 30 patients with abnormal MRI findings, and true-negative in $2(66.6 \%)$ patients of the compared 3 patients with no abnormal MRI findings. Morphological analysis revealed overall $93.9 \%$ sensitivity and $66.6 \%$ specificity.

\section{TABLES}

Table 1: Distribution of patients according to age.

\begin{tabular}{ccc}
\hline Age & Patients number & Percentage \% \\
\hline$<20$ years & 13 & 26 \\
\hline $20-40$ years & 21 & 42 \\
\hline 41-60 years & 16 & 32 \\
\hline Total & 50 & 100
\end{tabular}

Table 2: Distribution of patients according to the site of knee injuries.

\begin{tabular}{ccc}
\hline Injury & Number of patients & Percentage \% \\
\hline ACL & 19 & 38 \\
\hline PCL & 2 & 4 \\
\hline Meniscal & 18 & 36 \\
\hline Collateral ligaments & 12 & 24 \\
\hline Bone & 13 & 24 \\
\hline Cartilage & 12 & 14 \\
\hline Muscular/tendinious & 7 & 6 \\
\hline Retinacular & 3 & 6 \\
\hline Popliteal cyst rupture & 3 &
\end{tabular}

Table 3: Distribution of patients according to the type of sport.

\begin{tabular}{ccc}
\hline Sport & Patients number & Percentage \% \\
\hline Soccer & 11 & 23.4 \\
\hline American football & 7 & 14.3 \\
\hline Running & 7 & 14.3 \\
\hline Tennis & 3 & 6.4 \\
\hline Skating & 3 & 6.4 \\
\hline Surfing & 3 & 6.4 \\
\hline Bicycling & 2 & 4.3 \\
\hline Martial arts & 2 & 4.3 \\
\hline Hiking & 2 & 4.3 \\
\hline Softball & 1 & 2.1 \\
\hline Aerobics & 1 & 2.1 \\
\hline Golf & 1 & 2.1 \\
\hline Gymnastics & 1 & 2.1 \\
\hline Volleyball & 1 & 2.1 \\
\hline Wrestling & 1 & 2.1 \\
\hline
\end{tabular}


Table 4: Sensitivity and specificity of MRI for the different knee injuries.

\begin{tabular}{ccc}
\hline Injury & Sensitivity \% & Specificity \% \\
\hline ACL & 86 & 90 \\
\hline PCL & 100 & 100 \\
\hline Meniscus & 80 & 85 \\
\hline Collateral ligaments & 85 & 90
\end{tabular}

\section{Figures}

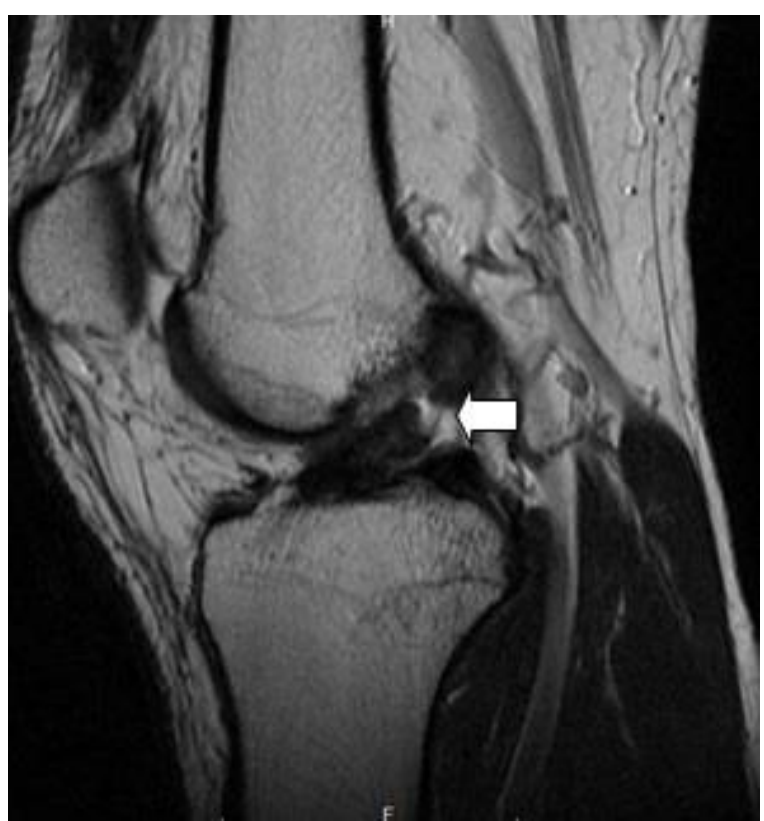

Fig.(1)

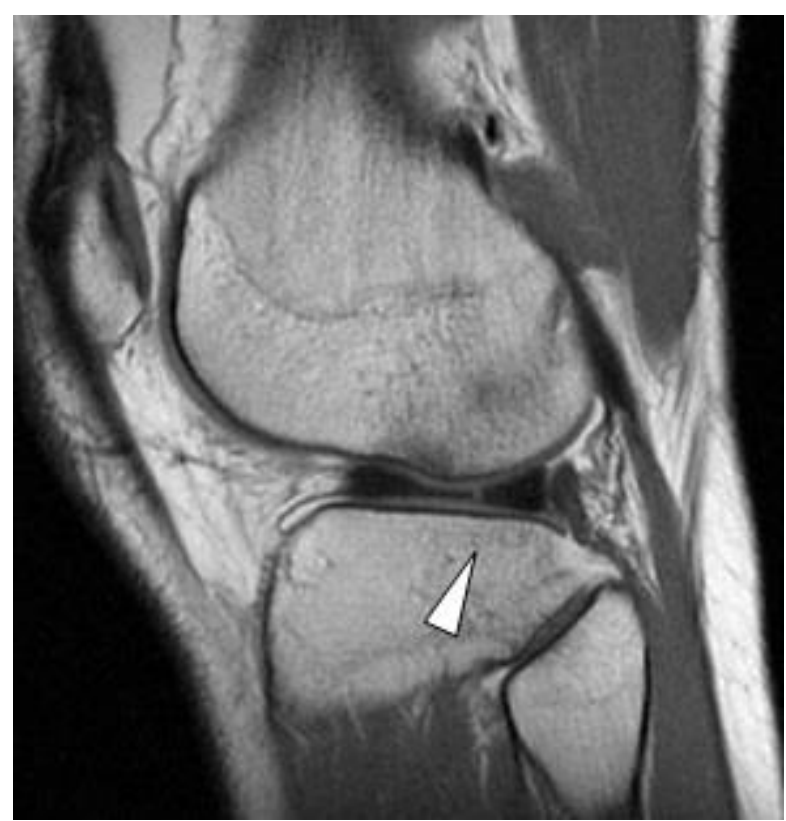

Fig.(2)

Fig. 1: Sagittal T2 image showing a complete tear of the proximal aspect of the anterior cruciate ligament near the femoral attachment replaced by high signal intensity (arrow).

Fig. 2: Sagittal PD image showing a small radial tear at the junction of the body and posterior horn of the lateral meniscus (arrowhead). Also, there is an osteochondral fracture at the midportion of the lateral femoral condyle with associated mild depression of the subchondral bone plate and opposing bone marrow edema. In addition, moderate amount of fluid effusion is noted in the suprapatellar pouch. 


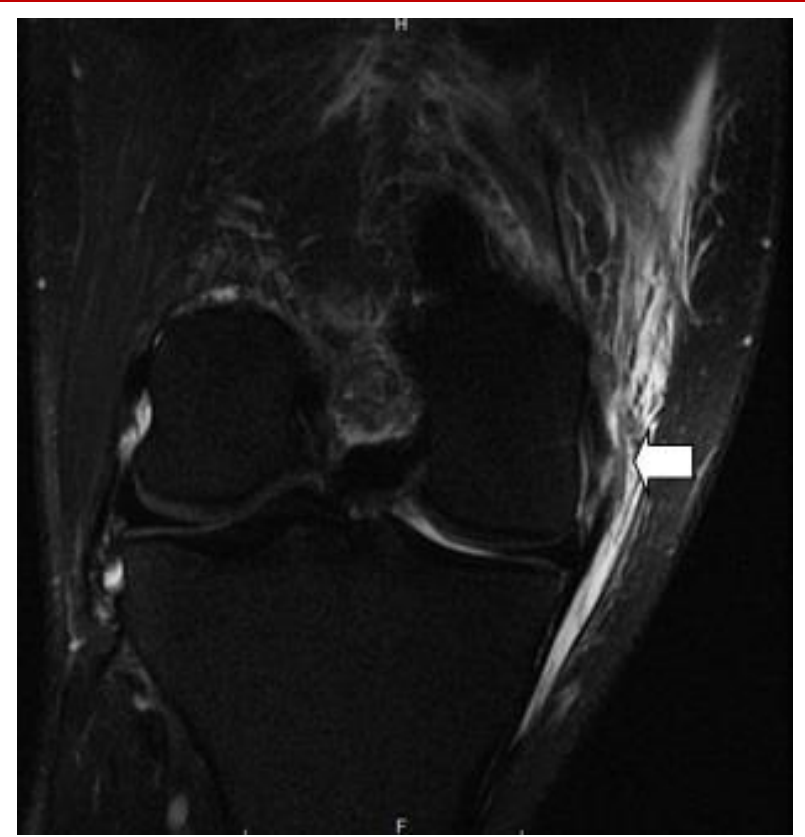

Fig.(3)

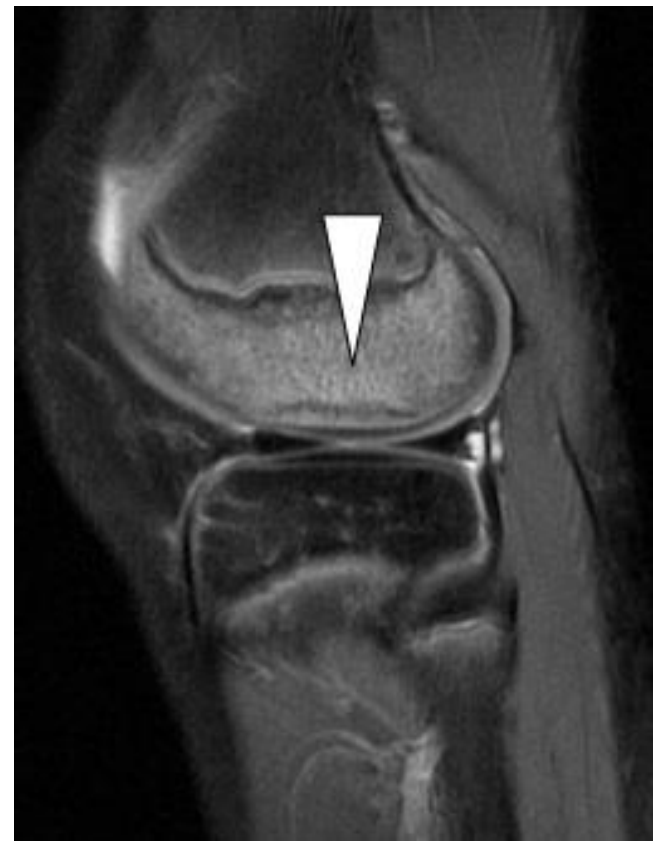

Fig.(4)

Fig. 3: Coronal fat suppressed $\mathrm{T} 2$ image showing high grade recent partial tearing of the tibial collateral ligament near its femoral attachment with surrounding edema (arrow).

Fig 4: Sagittal fat suppressed PD image showing a linear hypointense signal in the lateral femoral condyle with surrounding marrow edema denoting a subchondral trabecular bone fracture (arrowhead).

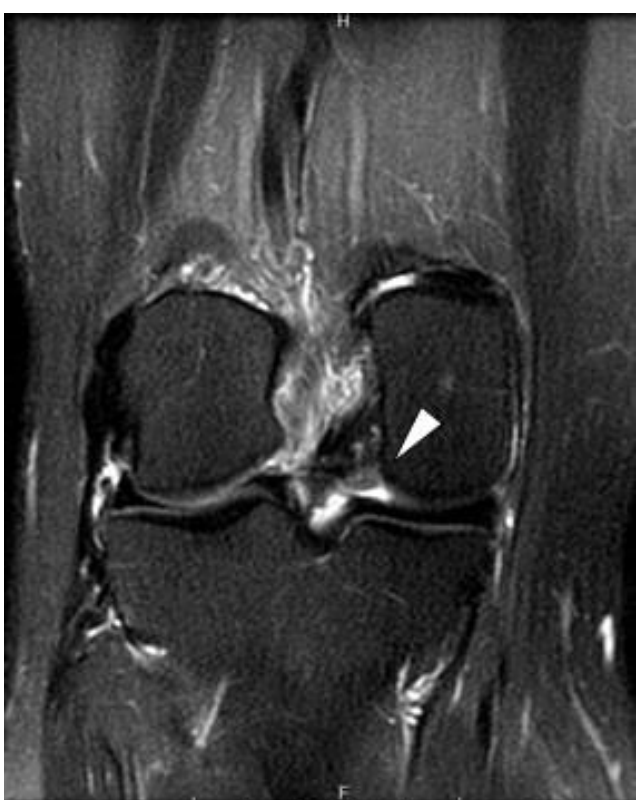

Fig.(5)

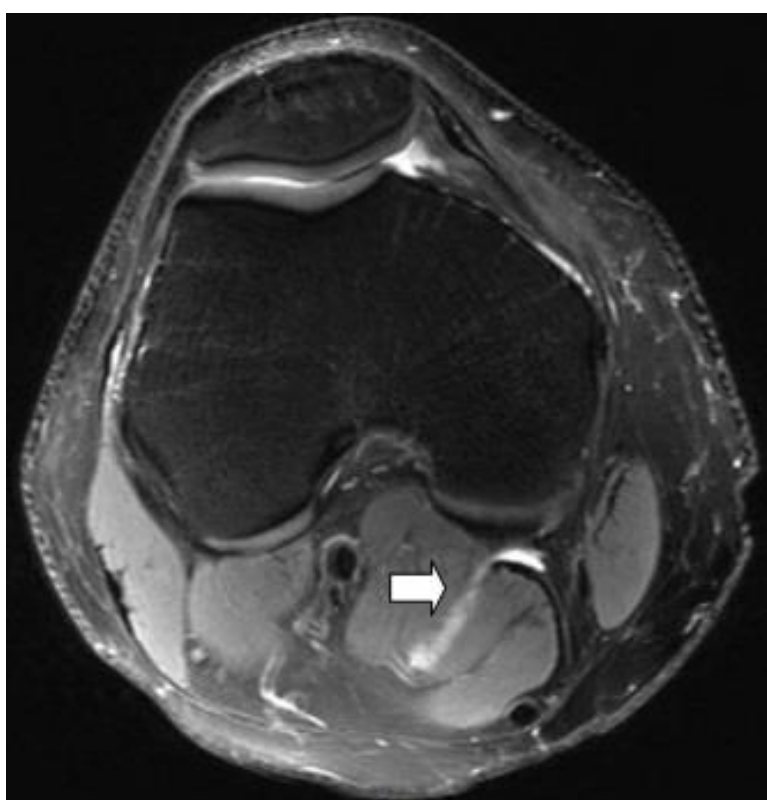

Fig.(6)

Fig 5: Coronal fat suppressed $\mathrm{T} 2$ image showing a focal moderate grade cartilage loss noted at the inner aspect of the medial femoral condylar cartilage (arrowhead).

Fig 6: Axial fat suppressed PD image showing a small popliteal cyst, associated with extensive intermuscular leakage of fluid inferiorly between the medial head of gastrocnemius muscle and the semimebrenosus muscle (arrow). 


\section{DISCUSSION}

The purpose of this study is to demonstrate the value of MRI in diagnosing the sports injuries of the knee joint. The results were compared with arthroscopic findings as the final determination for the sensitivity and specificity.

In this study the ages of the patients ranged between 15 and 55 years. Most of the patients were between 20 and 40 years old representing $42 \%$ of the patients with a mean age of 29.68 years. Males represented $76 \%$ while females represented $24 \%$. These results agree with the study of Majewski et al, 2006 (7) which was a 10 years study of 6434 athletic knee injuries as it demonstrated that $40 \%$ of patients were between 20 and 40 years old and $73 \%$ were males. Also, the study of Laoruengthana et al, 2012 (8) had the mean age of 36.7 years (ranging from 18-75 years) with the males representing $60 \%$ and females representing $40 \%$.

On the other hand, the study of Avcu et al, 2010 (9) had the ages of the patients ranged between 1 and 74 years with a mean age of 43.3 years, which is higher than our study mean age.

According to Lim et al, 2008 (3), sports injuries may affect any of the knee structures, including ligaments, menisci, bones, cartilage and peri-articular soft tissues. In the present study, regarding the site of knee injury, we found that ACL injuries were the most common knee injuries among the patients (19 patients representing 38\%), followed by meniscal injuries (18 patients representing 36\%) and collateral ligament injuries (12 patients representing 24\%). However, the least encountered injuries were the PCL injuries (2 patients representing 4\%).

Comparing our results with previous studies such as the study of Majewski et al, 2006 (7), they reported injuries distribution of ACL lesions (20.3\%), Meniscus lesions (14.5\%), Collateral ligaments $(9 \%)$ and PCL lesions $(0.65 \%)$. Also, the study of Manoj et al, 2014 (10), out of an 80 patients 35(43.75\%) showed ACL injury, $23(28.75 \%)$ showed medial meniscus tear, $11(13.75 \%)$ showed lateral meniscus tear, $4(5 \%)$ showed PCL injury, 4 (5\%) showed MCL injury and $3(3.75 \%)$ showed LCL tear. Moreover, Webb and Corry, 2000 (11) had in their study injuries distribution of ACL lesions (46\%), meniscal lesions (11\%), collateral ligaments lesions (31\%) and PCL lesions (4\%).

We found that all these studies had similarities with our study in that ACL lesions were the most common knee lesions and that PCL lesions were the least common ones. In addition, the incidence of meniscal lesions came after the ACL lesions except in the study of Webb and Corry, 2000 (11) which had higher collateral ligaments lesions than meniscal lesions.

Christopher et al, 2008 (12) stated that the knee is the largest joint in the body and is a relatively unstable and intricate joint with numerous tendinous, ligamentous, and meniscal attachments, which makes it particularly vulnerable to complex injuries after trauma. Moreover, according to Lim et al, 2008 (3), relatively few injuries involve isolated structures, with complex injuries affecting multiple structures being much more common. The present study agrees with Christopher et al and with Lim et al as from those 47 patients with abnormal MRI findings, 16 patients (34\%) were represented with isolated injury while 31 patients $(66 \%)$ were represented with combined injuries. The study of Webb and Corry, 2000 (11) also indicated a higher occurrence of complex injuries (81\%) and lower incidence of isolated injuries (19\%).

In our study, the distribution of sports causing knee injuries were soccer (11 patients) representing $23.4 \%$, American football (7 patients) representing $14.3 \%$ and running (7 patients) representing $14.3 \%$. Knee sports injuries were also caused by other sports as tennis, skating, surfing, bicycling, martial arts and hiking. The study of Majewski et al, 2006 (7) concluded that soccer represented (35\%) and skating (26\%) from the sports causing knee injuries. Other activities also included American football, tennis, gymnastics, martial arts, handball, volleyball and basketball. Despite the higher percentage of knee injuries with soccer in their study than in our study, soccer is the most common sport to cause knee injuries as in our study. On the other hand, the incidence of knee sports injuries with some sports such as skating is variable according to where the study was done.

Nikolaou et al, 2008 (13) studied 46 patients and concluded that the diagnostic power of MRI in knee injuries was substantially more than physical examinations. However, in other studies there were contradictory findings. Husudhan et al, 2008 (14) in the UK studied 109 injured knees. In their study the physical examinations, with the exception of meniscus tears, were superior to MRI results. In a study in Mashhad on 92 patients with knee injuries, Mazlomy et al, 2007 (15) noted similar results and reported a high accuracy for 
clinical examinations. Behairy et al, 2009 (16) is an Egyptian study of 70 patients noted high diagnostic accuracy of both physical examination and MRI, and in most cases, only slight differences existed between the two methods, which was also confirmed in a study by Thomas et al, 2007 (17).

Regarding knee MRI, in most of the studies and in our study as well, the base of reference is arthroscopy. This presupposes that arthroscopy is $100 \%$ accurate and allows for the diagnosis of every possible knee pathology. This is not always the case. Arthroscopy is a technical demanding procedure and the results are varying according to surgeons' experience, especially in difficult cases. Crawford et al, 2007 (18) stated that MRI is the most appropriate screening tool before arthroscopy. It is preferable to diagnostic arthroscopy in most patients because it avoids the surgical risks. Also concerning the economic burden especially in a country like Egypt, MRI may decrease unjustified arthroscopies.

On the other hand, Halinen et al, 2008 (19) referred to the Causes of false MRI interpretations as many, including technical and anatomy-related causes. Some errors in the MRI interpretation may be related to problems in the use of arthroscopic findings as the standard of reference, including lack of imaging of some tears under the surface of the posterior horn, reliance on probing or compression to diagnose tears, and differences in descriptive terminology for disease of or damage to the meniscus . One arthroscopist may describe meniscal free edge pathology as fraying and another as a small tear. According to Manoj et al, 2014 (10) the explanation for discrepancy between MRI and arthroscopy are misinterpretation of normal anatomy like meniscofemoral ligaments ...etc, the presence of intrasubstance tears, operator dependence, presence of loose bodies. The study of Peleg et al, 2006 (20) stated that major causes for the differences in the results were related to different skill levels of personnel involved in MRI interpretation, arthroscopy and clinical examination. The difference in technique used for the MRI is of importance. Studies have shown that if the examination is performed by a skilled technician, the results will be accurate.

The sensitivity and specificity of MRI for diagnosing ACL lesions in this study were $86 \%$ and 90\% respectively, which agrees with Manoj et al, 2014 (10) as their study revealed $86.6 \%$ sensitivity and $90 \%$ specificity for ACL lesions evaluation by
MRI. This also agrees with Khanda et al, 2008 (21) as they observed in their study sensitivity and specificity for the ACL MRI of $86.67 \%$ and $91.43 \%$ respectively. Moreover, Rayan et al, 2009 (22) presented similar sensitivity results, as they reported 85.4\% sensitivity of the MRI for diagnosing ACL lesions. On the other hand, the study of Laoruengthana et al, 2012 (8) which was performed at the center in Phitsanulok demonstrated that the sensitivity and specificity of the MRI in detecting the complete tear of the ACL injury was $90.9 \%$, and $84.6 \%$ respectively.

In the present study the most common sign of ACL Injury in MRI was hyperintensity which is relatively common to be described in the literature. Among other signs were actual interruption of fibers and ligamentous laxity. This agrees with Manoj et al, 2014 (10) which revealed the MRI hyperintensity as the main finding in ACL injuries.

Regarding the PCL, surgeons must always bear in mind that PCL is difficult to investigate during arthroscopy because of its anatomic position, and many times there are arthroscopic false negative results. On the other hand, MRI has high sensitivity and specificity in detecting PCL lesions. Many studies refer accuracy in ruptures higher than $90 \%$ such as the studies of Laoruengthana et al, 2012 (8), Nikolaou et al (13), 2008 and Winters et al, 2005 (23). In our study, we evaluated only 2 PCL injuries and all were identified by MRI with $100 \%$ sensitivity and specificity. Even though our results agree with Witonski, 2008 (24) and Vaz et al, 2005 (25) studies, the number of cases is too small for statistical significant conclusions.

In this study, MRI showed that the sensitivity of meniscal MRI is $80 \%$ with false positive results in 2 patients $(20 \%)$ of the meniscal injuries and these results demonstrate a sensitivity less than (Kuikka et al, 2009) (26) and (Ramnath et al, 2006) (27) Which reported sensitivity of MRI of $91.7 \%$. On the other hand, the specificity of meniscal MRI in this study is $85 \%$ which agrees with the studies of Kuikka et al, 2009 (26) and Ramnath et al, 2006 (27). Their studies reported $86 \%$ and $87.1 \%$ specificity respectively for meniscal MRI.

Nikolaou et al, 2008 (13) stated that there are several explanations for the misleading results of MRI regarding the menisci. Firstly, meniscal tears and meniscus degenerative changes have the same appearance in MRI, by giving high signal within the meniscus. Diagnosis then depends on the 
expansion of the high signal line towards meniscus articular surface. Moreover, one of the most frequent causes for false positive MRI regarding the lateral meniscus is the misinterpretation of the signal coming from the inferior knee artery. Often, the popliteal bursa or Humphrys' ligament may mimic posterior lateral meniscus tears as well.

Some authors such as Helms, 2002 (28) reported that specific imaging sequences improve the sensitivity and specificity for detecting meniscal and ligamentous tears. Fast spin-echo (FSE) imaging, used in conjunction with fat-suppression (FS) MR techniques, has extended the sensitivity and specificity of MR in the detection of articular cartilage injuries and the evaluation of meniscal tears.

In this study, the sensitivity of MRI in diagnosing knee lesions compared to arthroscopy is $93.3 \%$ which agrees with the studies of Manoj et al, 2014 (10) and the study of Laoruengthana et al, 2012 (8) that showed sensitivity higher than $90 \%$. On the contrary, in our study the specificity of MRI in diagnosing knee lesions compared to arthroscopy is $66.6 \%$ with PPV of $93.3 \%$ and NPV of $66.6 \%$ which does not agree with the study of Crawford et al, 2007 (18) that stated that MRI has a higher specificity $(92.8 \%)$ than sensitivity $(82.5 \%)$, and a higher NPV (92.2\%) than the PPV (82.5\%).

Bradley, 2006 (4) concluded that over the past 20 years, magnetic resonance imaging (MRI) has become the premier, first-line imaging study that should be performed in the evaluation of the painful knee. Lim et al, 2008 (3) also concluded that MRI is now widely used for imaging injuries of internal structures of the knee, and has replaced conventional arthrography and diagnostic arthroscopy. Although arthroscopy has been considered the Gold Standard in knee sports injuries evaluation and diagnosis of meniscal and ligamentous injuries, MRI remains a reliable noninvasive modality that can reduce the use of diagnostic arthroscopy.

\section{CONCLUSION}

Knee sports injury is a very common condition that is frequently encountered both in general practice and in the hospital setting. Sports knee injuries represent one of the problems facing athletes which may change their life style and the early diagnosis is of a great value in the treatment of these injuries MRI can improve the diagnostic accuracy, which may reduce the amount of time athletes cannot play in games or practice and may accelerate rehabilitation after injury. MRI represents the optimal imaging tool in the evaluation of the sports-related knee injuries, which has been shown to be an accurate and non invasive method of diagnosing ligament, meniscal, cartilage, tendinous and muscular knee injuries.

In our study we examined fifty patients with MRI and took full clinical history. Then we compared the results of thirty three of these patients with arthroscopy. This study demonstrates a $86 \%$ sensitivity and $90 \%$ specificity for the ACL injuries, $80 \%$ sensitivity and $85 \%$ specificity for the meniscal injuries and $100 \%$ sensitivity and specificity for PCL injuries. This study results agree with many of the preliminary studies and both imply a high accuracy of MRI in the diagnosis of ligamentous and meniscal knee injuries.

In conclusion, MRI is non-invasive and accurate so is superior to the diagnostic arthroscopy and we recommend MRI as a consequential diagnostic tool for the evaluation of knee sports injuries.

\section{REFERENCES}

1. Frisch A, Croisier JL, Urhausen A et al.: Injuries, Risk Factors And Prevention Initiatives In Youth Sport.Br Med Bull, 2009 ;92(1): 95-121.

2. Caine D, Caine $\mathrm{C}$, Maffulli $\mathrm{N}$ : Incidence and Distribution of Pediatric Sport Related Injuries. Clin J Sport Med, 2006;16:500-513.

3. Lim S et al: Sports Medicine: Magnetic Resonance Imaging of Sports Injuries of the Knee. Annals J, Apr 2008;37(4):15-23.

4. Bradley W: Knee Pain: MRI of Sports Injuries. Applied radio J, Feb 2006;35(2):3-9.

5. Karachalios T, Hantes M, Zibis AH et al: Diagnostic Accuracy Of A New Clinical Test (The Thessaly Test) For Early Detection Of Meniscal Tears. J Bone Joint Surg, 2005;87:955-962.

6. Stoller DW: Magnetic Resonance Imaging in Orthopedics and Sports Medicine, Copyright Lippincott Williams \& Wilkins, 3rd Edition, 2007; chap 4, P494-495.

7. Majewski M, Susanne H, Klaus S: Epidemiology of athletic knee injuries: a 10-year study. Knee. 2006;13(3):184-188.

8. Laoruengthana A, Jarusriwanna A: Sensitivity and Specificity of Magnetic Resonance Imaging for Knee injury and Clinical Application for the Naresuan University Hospital. J Med Assoc Thai 2012; 95 (Suppl. 10): S151-S157.

9. Avcu S, Altun E, Akpinar I, Bulut MD, Eresov K, Biren T: Knee Joint Examinations by Magnetic Resonance Imaging: The Correlation of Pathology, Age and Sex. North Am J Med Sci 2010; 2: 202-204. 
10. Manoj MK, Ray B, Francis J: Correlation between MRI and arthroscopic findings in injuries of knee joint. Kerala Journal of Orthopedics 2014;18:21.

11. Webb $\mathrm{J}$ and Corry I: Injuries of the sporting knee. Br J Sports Med 2000;34:227-228.

12. Christopher J. Gottsegen, Benjamin A. Eyer, Eric A. White, et al: Avulsion Fractures of the Knee: Imaging Findings and Clinical Significance. RadioGraphics, Oct 2008; 28:1755-1770.

13. Nikolaou VS, Chronopoulos E, Savvidou C, Plessas S, Giannoudis P, Efstathopoulos N, et al.: MRI efficacy in diagnosing internal lesions of the knee: a retrospective analysis. J Trauma Manag Outcomes. 2008;2:4.

14. Husudhan T, Kumar T, Bastawrous S, Sinha A: Clinical examination, MRI and arthroscopy in meniscus and ligamentous knee Injuries - a prospective study. J Orthop Surg Res. 2008;3:19.

15. Mazlomy M, Makhmalbaf H, Kashani omidi F, Mahvalati A: Comparison of clinical findings with arthroscopic findings in knee intra-articular injuries. Med J Mashhad Univ Med sci. 2007;49:421-426.

16. Behairy NH, Dorgham MA, Khaled SA: Accuracy of routine magnetic resonance imaging in meniscal and ligamentous injuries of the knee: comparison with arthroscopy. Int Orthop. Aug 2009;33(4):961-7.

17. Thomas S, Pullagura M, Robinson E, Cohen A, Banaszkiewicz P: The value of magnetic resonance imaging in our current management of ACL and meniscus injuries. Knee Surg Sports Traumatol Arthrosc. 2007; 15:533 - 536.

18. Crawford R, Walley G, Bridgman S, et al.: Magnetic resonance imaging versus arthroscopy in the diagnosis of knee pathology, concentrating on meniscal lesions and ACL tears: a systematic review. Br Med Bull. 2007;84:5-23.

19. Halinen J, Koivikko M, Lindahl J, Hirvensalo E: The Efficacy of Magnetic Resonance Imaging in Acute Multi-ligament Injuries. International Orthopaedics (SICOT) 2008; 33:1733-1738.

20. Peleg B, Ely S, Hagai A, Nachman A, Arbel R: Accuracy of magnetic resonance imaging of the knee and unjustified surgery. Clin Orthop Relat Res. 2006;447:100-104.

21. Khanda GE, Akhtar W, Ahsan H, Ahmad N: Assessment of menisci and ligamentous injuries of the knee on magnetic resonance imaging: Correlation with arthroscopy. J Pak Med Assoc. 2008;58:537-40.

22. Rayan F, Bhonsle S, Shukla DD: Clinical, MRI, and arthroscopic correlation in meniscal and anterior cruciate ligament injuries. Int Orthop. 2009;33:129-32.

23. Winters K, Tregonning R: Reliability of magnetic resonance imaging of the traumatic knee as determined by arthroscopy. N Z Med J 2005; 118:U1301.
24. Witonski D: Acute traumatic hemarthrosis of the adult's knee -a diagnostic options in arthroscopic era. Literature review. Chir Narzadow Ruchu Ortop Pol. Sep-Oct 2008;73(5):339-43.

25. Vaz CE, Camargo OP, Santana PJ, et al.: Accuracy of magnetic resonance in identifying traumatic intraarticular knee lesions. Clinics (Sau Paulo). 2005;60:445-450.

26. Kuikka PI, Sillanpää P, Mattila VM, et al.: Magnetic resonance imaging in acute traumatic and chronic meniscal tears of the knee: a diagnostic accuracy study in young adults. Am J Sports Med. 2009;37:1003-80.

27. Ramnath RR, Magee T, Wasudev N, Murrah R: Accuracy of 3-T MRI using fast spin-echo technique to detect meniscal tears of the knee. AJR Am J Roentgenol. 2006;187:221-5.

28. Helms CA: The meniscus: recent advances in MR imaging of the knee. AJR Am J Roentgenol. Nov 2002; 179(5):1115-22. 


\title{
دور الفحص بالرنين المفناطيسى على الجهاز العضلى والحركى لمفصل الركبة فى تقييم الإصابات الرياضية بها
}

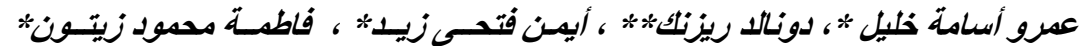

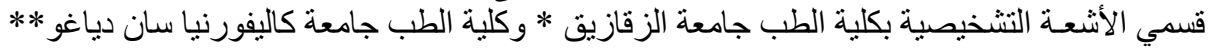 \\ الملخص العربي
}

مقدمة

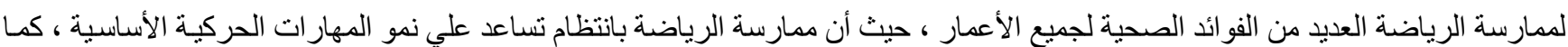

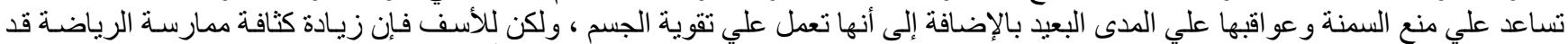

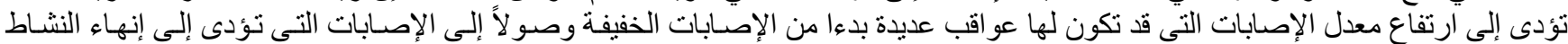
الرياضى.

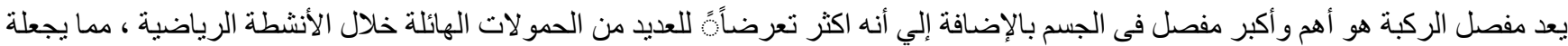

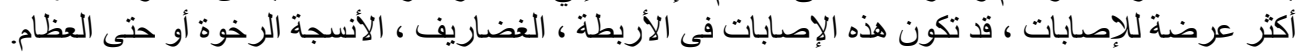

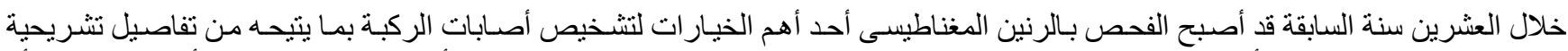

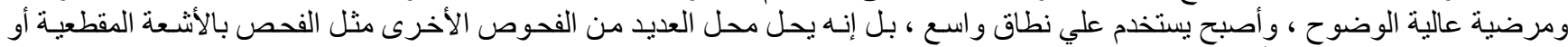

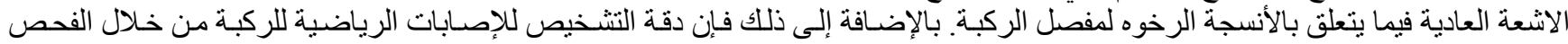

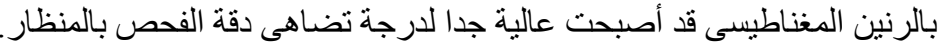

أهداف الاراسة تقييم دور الفحص بالرنين المغناطيسى على مفصل الركبة في حالات الإصابات الريات الرياضية بها.

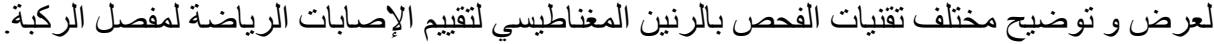

طرق و أدوات البحث

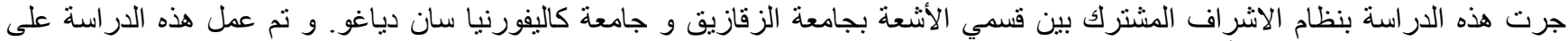

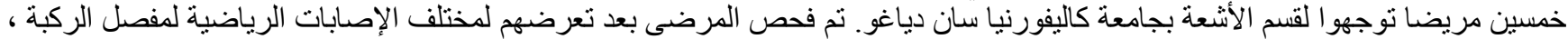

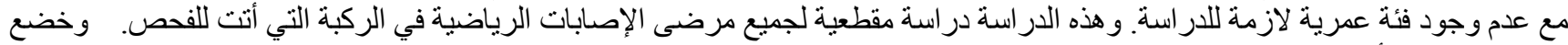

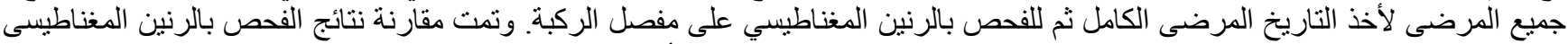
مع نتائج الفحص بالمنظار لثناثة و ثلاثثين حالة. وتمت مناقنة النتائج وجدولتها. كما أخذت مو افقة خطية لعمل الفحوص من كل مريض.

النتائج

تم عرض البيانات التي تم جمعها في الجداول و الرسوم البيانيـة المناسبة. وتم تحليل البيانات بو اسطة الكمبيوتر من خلال برنامج الإكسيل، وذلك باستخدام الأساليب الإحصائية المناسبة في النية

المناقشة

تمت مناقثة هذه النتائج ، بالاستعانة بالمر اجع و البحوث العلمية المنعلقة؛ مع توضيح الأسباب للحصول على مثل هذه النتائج، و تشـابهها أو اختلافها عن بعض المراجع. الخلاصة و التوصيات استمدت من نتائج هذه الدراسة.

الخلاصة و التوصيات

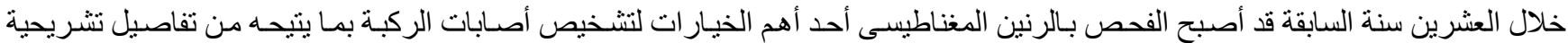

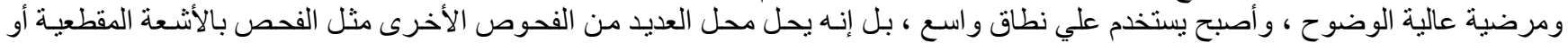

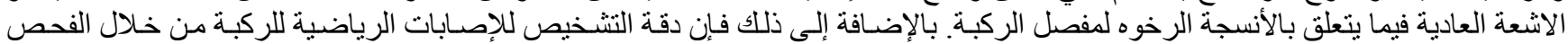

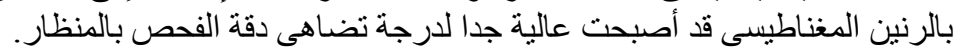

